\title{
Pedagogos da nação: reflexões sobre trajetórias e sociabilidades de bacharéis brasileiros a partir do periódico A Actualidade (1859-1861)
}

\section{Pedagogues of the nation: reflections on trajectories and sociabilities of Brazilian law graduates through the periodical A Actualidade (1859-1861)}

\author{
Matheus da Cruz e Zica*
}

\begin{abstract}
RESUMO
O presente artigo pretende analisar as circunstâncias que estruturam a articulação de três bacharéis: Bernardo Guimarães, Flávio Farnese e Lafaiete Rodrigues, que no início de 1859 se reuniram no Rio de Janeiro, Corte do Império do Brasil, para fundar uma folha liberal intitulada A Actualidade, com duração até 1861. Argumentamos que a passagem pela Faculdade de Direito de São Paulo foi uma das grandes responsáveis pela associação entre os três jovens originários de Minas Gerais, colaborando para uma centralidade do tema nacional quanto eixo da atividade jornalística que empreenderam, analisando atentamente a política educacional naquele contexto, e se posicionando a partir de um tom explicitamente educativo em relação aos seus leitores.
\end{abstract}

Palavras-chave: Bacharelismo. Imprensa. Educação. Política. Século XIX.

\footnotetext{
ABSTRACT

The present article intends to analyze the circumstances involving the articulation of three law graduates, Bernardo Guimarães, Flávio Farnese and

DOI: $10.1590 / 0104-4060.53222$

* Universidade Federal de Campina Grande. Programa de Pós-Graduação em História. Campina Grande, Paraíba. Rua Aprígio Veloso, nº 882. Bairro Universitário. CEP: 58.429-900. E-mail: matheusczica@gmail.com.
} 
Lafaiete Rodrigues, who met at the beginning of 1859 in Rio de Janeiro, the capital of the Empire of Brazil at that moment, to found a liberal "paper" entitled A Actualidade, lasting up to the year 1861. We sustain that their passage by the Law School of the University of São Paulo was one of the great factors responsible for the association between the three teenagers from Minas Gerais, defining the centrality of the theme "nation" as the axis of their journalism activity, for their carefully analysis of the educational policy in that context, and for an explicitly educational tone they adopted in relation to their readers.

Keywords: Law graduates. Press. Education. Politics. Nineteenth century.

\section{Introdução}

Após a independência, em 1822, aumenta o número de políticos em território brasileiro que "retiram os olhos" de Portugal e passam a tomar como referência outros países, como Inglaterra e França. O projeto da Academia de Direito de São Paulo, que se implanta em 1827, nasce inclusive com esse espírito de "superar o passado imediatamente colonial, formando, através do ensino jurídico, uma elite intelectual aberta à modernidade" (ADORNO, 1988, p. 95). Apesar de manter em sua primeira estrutura curricular "arcaicas noções de Direito Público Eclesiástico para ponderar as relações entre Igreja e Estado", não deixou de trazer também "uma grande inovação" ao incluir "uma cadeira de Economia Política, no quinto ano, muito antes do que na França" (ADORNO, 1988, p. 96).

O estabelecimento da Academia de Direito de São Paulo possibilitava aos estudantes, portanto, se aproximarem de novas ideias sobre o que seria a política, em oposição à antiga hegemonia "jus-naturalista da tradição coimbrã", com seus pressupostos universais e imutáveis - que, ambiguamente, segundo o autor, nunca deixou, no entanto, de ter força no currículo daquela instituição ao longo de boa parte do século XIX. (ADORNO, 1988, p. 95).

Contudo, apesar das ambiguidades e do peso da tradição, é preciso estar atento para o fato de que "os parlamentares brasileiros" que idealizaram a proposta do curso jurídico em 1825 - "muitos dos quais haviam freqüentado universidades européias" - estavam mais preocupados em superar a tradição e acreditavam que na faculdade poderia se constituir "uma elite política coerente, disciplinada, homogênea e devota às razões do Estado e ao poder público", em oposição ao personalismo característico do período anterior (ADORNO, 1988, p. 86). 
Segundo Schwarcz (1993, p. 142):

A partir de 1828 iniciavam-se os primeiros cursos, e de forma ascendente a profissão e a figura do bacharel tornavam-se estimadas no Brasil. O prestígio advinha, no entanto, menos do curso em si, ou da profissão strictu sensu, e mais da carga simbólica e das possibilidades políticas que se apresentavam ao profissional de direito.

Mas o processo de consolidação desse prestígio não se deu de maneira simplificada. Segundo Adorno (1988, p. 79):

Toda uma "trama" intrincada de relações e de práticas sociais constituiu o terreno sobre o qual se edificou o universo ideológico que fez emergir o principal intelectual da sociedade brasileira durante o século XIX: o bacharel. Tratou-se de um intelectual que se desenvolveu às expensas de uma vida acadêmica controvertida, agitada e heterogênea, construída nos interiores dos institutos e associações acadêmicos, que teve no jornalismo seu mais eficaz instrumento de luta e tornou viável a emergência de uma ética jurídica liberal, defensora das liberdades e da vigília permanente da sociedade. As Academias de Direito fomentaram um tipo de intelectual produtor de um saber sobre a nação, saber que se sobrepôs aos temas exclusivamente jurídicos e que avançou sobre outros objetos de saber.

Tanto Schwarcz (1993) quanto Adorno (1988), ressaltam com propriedade essa nítida relação que existiu entre os alunos formados nas faculdades de direito e a intervenção política no Brasil Império. Mencionada essa relação primordial, gostaria de destacar outras três características da formação desses bacharéis, também percebidas e ressaltadas por Adorno (1988, p. 79), que consideramos importantes para compreendermos melhor os caminhos trilhados por esses sujeitos após o período de formação: 1) a adoção do jornalismo como um eficaz instrumento de intervenção; 2) uma ética discursiva de defensoria das liberdades e de vigília permanente da sociedade; e, por fim, 3) compromisso com um saber sobre a nação que podia extrapolar temas exclusivamente jurídicos.

De fato, iremos encontrar muito claramente a marca desses três pontos na trajetória dos sujeitos que iremos trazer ao texto a seguir. Outra questão não ressaltada por Adorno (1988), mas que consideramos fundamental, merece ser acrescentada aos já referidos três pontos muito bem formulados pelo pesquisador 
citado: é a dimensão formativa/educativa que caracterizava a intervenção desses bacharéis na cena pública do século XIX. Fator que procuraremos ressaltar nesse artigo.

\title{
Imprensa como educadora e formadora da nação
}

Em 08 de junho de 1859, publicava-se, na cidade do Rio de Janeiro, uma matéria em tom de denúncia em relação à posição da imprensa diante da política da conciliação que vigorava naquele momento:

\begin{abstract}
A imprensa outrora tão livre, tão independente, a imprensa, a educadora do povo Brasileiro, que recebeu-a ignorante das mãos do despotismo colonial e em pouco fê-lo compreender todo o mecanismo do sistema representativo, todas as suas vantagens, a imprensa emudeceu. A liberdade, a civilização, o progresso, as instituições democráticas, a nobre luta das idéias perderam para ela todo o encanto. Infiel à sua missão ela não fez mais do que engrossar o coro da lisonja. O Poder, eis sua única idéia: agradar ao poder sua única ambição; o ouro do poder, sua fascinação constante. [...]

- A imprensa abandonou o povo que é pobre e rojou ante o poder que tem a chave do erário; deixou-se de ser livre, independente e patriótica e tornou-se mercenária! [...]. (A ACTUALIDADE, 08 jun. 1859, p. 3, grifo nosso).
\end{abstract}

Este trecho foi retirado de uma matéria cujo título era "Progresso do sistema representativo no Brasil", veiculada no $\mathrm{n}^{\circ} 26$ do jornal, ou folha, como preferiam dizer seus redatores, chamado A Actualidade ${ }^{1}$. Eram eles Flávio Farnese $^{2}$, Lafayette Rodrigues Pereira ${ }^{3}$ e Bernardo Guimarães ${ }^{4}$. Os três mineiros e bacharéis, pela Faculdade de Direito de São Paulo, fundaram o referido jornal na cidade do Rio de Janeiro, então Corte do Império, no início de 1859. Este

1 Os artigos do jornal A Actualidade, publicados entre os anos de 1859 e 1861, estão microfilmados na Biblioteca Nacional-RJ.

2 Sabe-se que nasceu na cidade do Serro (MG), mas o ano de nascimento é incerto.

3 Nasceu em Queluz (MG), em 28 de março de 1834.

4 Bernardo Joaquim da Silva Guimarães nasceu em 1825, na então capital da Província de Minas Gerais, Ouro Preto. 
impresso semanal apresentava-se como liberal; discutia sobre política, decisões do Império, literatura e legislação. Além de difundir notícias da Corte, publicava também notícias de outras províncias, e, na maioria das vezes, de Minas Gerais. Provavelmente por causa das repercussões acaloradas de suas matérias, os redatores publicaram em 23 de abril de 1859 , no $\mathrm{n}^{\circ} 14$, a seguinte nota:

Desejosos de tomar sobre nós francamente a responsabilidade dos artigos que escrevemos a fim de que não sirvam eles de meio de especulação e intriga política, como já tem acontecido para comprometer pessoas inteiramente estranhas a esta redação resolvemo-nos a estampar de hoje em diante nossos nomes no frontispício de nossa folha. Declaramos que todos os artigos de redação que d'ora em diante se publicarem, bem como os que até aqui têm sido publicados nessa folha, são devidos à pena de qualquer dos redatores acima mencionados. Se algum mal pode deles resultar desejamos que recaia unicamente sobre nós que somos seus redatores. (A ACTUALIDADE, 23 abr. 1859, p. 1).

Na passagem anterior a esta citação, está evidenciada a presença de todos os pontos levantados por Adorno (1988) para uma compreensão mais acurada das características da formação dos bacharéis da Faculdade de Direito de São Paulo ao longo do século XIX. Primeiro, devemos mencionar a adoção do jornalismo como a forma que os três bacharéis recém-formados elegeram para atuarem na cena pública, utilizando-o inclusive para refletirem sobre o próprio fazer jornalístico em suas páginas. Em segundo, diríamos da postura vigilante e denunciante presente na citação e que perpassa todo o periódico de maneira geral. Por último, a presença de reflexões sobre temas não estritamente jurídicos, como opiniões sobre a história do Brasil, a política, o papel da imprensa naquele contexto e, principalmente, a educação conforme veremos a seguir.

Como já dissemos, no entanto, queremos chamar a atenção para outra característica muito clara na citação, embora não tão explorada pelos pesquisadores para se compreender a atividade desses bacharéis do século XIX, qual seja a preocupação com a dimensão formativa/educativa que perpassava a atuação desses sujeitos no espaço público. O veículo jornal é entendido pelos três bacharéis mineiros em questão como educativo. Conforme veremos ao longo do texto, não é esporádica a referência à imprensa como "a educadora do povo brasileiro", imagem utilizada pelos redatores na citação que trouxemos anteriormente.

No século XIX, outras instituições, ao lado das poucas escolas, tinham papel importante na divulgação da ilustração ou na educação da população, 
uma dessas instituições foi o jornal (PALLARES-BURKE, 1998). O conteúdo dessa "pedagogia bacharelesca", presente em A Actualidade, divide-se em duas direções que se entrecruzam: a constituição de uma sensibilidade moderna, em termos de participação política (postura de vigilância em relação à coisa pública), e a construção de uma consciência nacionalista (um saber sobre a nação). A finalidade da educação que propunham ia em direção à conquista do que consideravam ser o progresso nacional naquela conjuntura.

Hélder Garmes (1993), visitando periódicos escritos por alunos da Faculdade de Direito do Largo São Francisco, focou seu estudo de mestrado no jornal intitulado Ensaios Literários e flagrou o estudante Bernardo Guimarães escrevendo em suas páginas, entre 1847 e 1850 . Era, pois, com esse tipo de experiência que os três bacharéis mineiros contavam ao decidirem fundar uma folha na Capital do Império.

Os três editores mineiros, assim como vários da época, também explicitavam a intenção de formar seus leitores por meio de sua folha. Demonstravam com clareza esta intenção em vários textos publicados, inclusive nos que tratavam de crítica literária, utilizando-os como um projeto explícito de pensar e construir, junto dos leitores, uma literatura nacional e a própria nação. A respeito da crítica literária, assim diziam:

Julgamos que a ela compete uma tarefa muito ativa, uma missão importante no desenvolvimento literário de um povo. [...] Cumpre quebrar este silêncio, despertar o publico dessa profunda indiferença, com que soe acolher os produtos de nossa literatura. - Bons ou maus eles devem ser estudados, e submetidos aos juízos da crítica, para que os talentos inexperientes conheçam os escolhos, que devem evitar, e os modelos, que podem adoptar. (A ACTUALIDADE, $1^{\circ}$ out. 1859, p. 2$)^{5}$.

Não queriam formar apenas os leitores, mas também os escritores da nova nação. A este respeito os redatores ainda afirmam que:

Alentar e promover pelos meios ao nosso alcance a cultura das letras em nosso país, procurar vulgarizar o gosto literário por meio de uma crítica franca, imparcial e sincera, constitui também uma das partes da 
tarefa que tomamos sobre nossos ombros, quando encetamos a carreira do jornalismo.

As letras formam e fortificam o espírito nacional, e tornam-se ao mesmo tempo o seu mais belo e fiel transunto. O maior ou menor grau de perfeição, a que tem atingido, dão a medida do grau do vigor e desenvolvimento a que tem chegado uma nacionalidade qualquer. [...] Entre nós, nação de ontem, as belas letras também se acham na infância. O espírito nacional, ainda não bem pronunciado, ainda não transparece em nossa literatura de um modo enérgico e original. Nossa excessiva admiração pelos monumentos da moderna literatura da Europa, dessa sociedade colocada em condições diametralmente opostas às nossas, nos tem feito abandonar as próprias inspirações, para entregar-nos ao estudo e imitação de uma literatura, a qual, se bem que rica e brilhante não tem deixado de contribuir para dar uma direção falsa e forçada ao espírito de nossa literatura nacional. (A ACTUALIDADE, $1^{\circ}$ out. 1859 , p. 2).

A Literatura Nacional seria para eles, então, uma ação e, ao mesmo tempo, um painel. Ou seja, uma ação, no sentido de construir a nação (singular e civilizada), e um painel, no sentido de que ali a nação (com uma certa identidade fixada) pode ser vista, acessada, visitada. Além do mais, nesse painel a nação estaria não só mais próxima de seus integrantes, como, também, representada de uma forma bela e brilhante. Note-se, aqui, a plena consciência, que os redatores apresentam, da artificialidade desta construção; a autoconsciência de que um escritor pode forjar a nação.

A título de conclusão, reafirmam a missão que eles próprios tomaram para si:

Portanto, malgrado os preconceitos que contra ela existem, julgamo-la sumamente necessária para formar e dirigir o gosto literário. [...] Com o intuito pois de fazer nascer algum interesse mais vivo pelo progresso de nossas letras, sufocadas sob a atmosfera pseudo da indiferença, e quase consideradas pelo positivismo da época como a maior das futilidades da vida, começaremos a passar em revista os produtos mais notáveis da nossa literatura nacional contemporânea. Levados somente pelo culto das letras, e pelo desejo de vê-las prosperar entre nós, aos nossos juízos presidirá sempre a mais completa imparcialidade. (A ACTUALIDADE, $1^{\circ}$ out. 1859 , p. 2$)$. 
É importante, portanto, ampliarmos nossa noção de educação para além do escolar para compreendermos esse fenômeno no século XIX. Dois pontos devem ser levados em conta: 1) as representações culturais circulantes nos mais diferentes espaços sociais - e por meio dos mais diferentes veículos - têm, de certa maneira, um poder formativo ou, como prefere Louro (2000), um poder pedagógico; e 2) não só as crianças, mas também os adultos estão imersos em "processos educativos" durante quase todo o tempo. Esse reconhecimento trouxe uma renovação à área de História da Educação, aos nossos olhos, muito interessantes, em termos de fontes, temáticas e enfoques.

Guacira Lopes Louro (2000) fala de uma pedagogia cultural do cinema, voltada sobretudo para jovens e adultos ao longo de todo o século XX. Carla Simone Chamon (1996), por sua vez, vai dizer de uma pedagogia dos sentidos contida nos festejos cívicos, direcionada aos cidadãos mineiros da primeira metade do século XIX; enquanto Carolina Mafra de Sá (2009) demonstra como o teatro em Minas Gerais, no início da segunda metade do século XIX, foi investido, por seus contemporâneos, de uma função educativa, visto como sendo capaz de ensinar muitas virtudes aos cidadãos que compareciam às peças. Todas essas "pedagogias" atingiam um público amplo e difícil de ser especificado, a não ser pelo fato de que era composto, sobretudo, por adultos.

Mas além de textos com forte caráter de formação, nas páginas d'A $A c$ tualidade circulavam também muitas notícias a respeito das províncias e em especial sobre a mineira, conforme já havíamos ressaltado. Talvez, por isso mesmo, não raro, podemos ver nas publicações várias correspondências vindas de diversas regiões de Minas Gerais. Assim como indica a pesquisa realizada por Barbosa (2007, p. 83), a nossa também tem "desmentido a concepção corrente, segundo a qual as províncias viviam culturalmente isoladas". A autora comenta que a pesquisa, em jornais e periódicos do século XIX, tem revelado não só uma ligação forte entre a corte e as províncias, mas também "um intenso movimento entre as províncias, o que incluía a troca de jornais, o recebimento de livros, a crítica literária [...]." (BARBOSA, 2007, p. 83).

Faria Filho sugere que os três mineiros, pelo fato de estarem irmanados num mesmo projeto jornalístico, político e cultural, escrevendo na Corte, merecem um estudo mais aprofundado, sobretudo em relação à ação prática que desenvolveram. Sua hipótese é de que o jornal seria a expressão de um projeto político de um grupo de mineiros que "quer dar a ver e defender os interesses da província e propor articular um projeto político-cultural nacional.” (FARIA FILHO, 2004, p. 12). Esse exemplo torna problemática uma concepção corrente que demarca fronteiras estritas entre o que é nacional e o que é regional. Divisões que são retomadas inclusive (e com certa frequência) em discursos atuais. 


\section{Política educacional em questão}

Ao falarem de seu próprio ofício - a imprensa - na metalinguística, matéria intitulada "Governo sem imprensa" (21/01/1860), os bacharéis mineiros vão deixar bastante clara a concepção que tinham da importância da publicidade em regimes políticos modernos, divulgando essa premissa no jornal. Começam denunciando a obscuridade dos atos governamentais:

É inconcebível, que em um país regido pelo sistema representativo, sistema essencialmente de discussão e publicidade, o governo possa subsistir sem uma imprensa a seu serviço, sem um órgão oficial, que exponha suas vistas, explane sua política, explique suas medidas, e as justifique, quando sejam agredidas. (A ACTUALIDADE, 21 jan. 1860, p. 1).

A imprensa aparece assim como parte central nessa forma moderna de se compreender a política. Nessa ocasião os três bacharéis, em sua postura vigilante, apresentam-se como os defensores de duas, para eles, intocáveis vítimas: a causa pública e a ética na imprensa.

Desgraçado o país, em que a arena das discussões ficasse fechada por tão largo prazo. A opinião pública, vigilante e severa, como deve ser em países representativos regularmente organizados tem obrigação de acompanhar constantemente com a sua censura todos os atos da administração, e não perdê-la de vista por tão longo tempo, sem risco de comprometer a causa pública.

$[\ldots]$

A criação de órgão oficial é hoje uma necessidade indeclinável para o gabinete; e é muito mais digno do governo de uma nação civilizada, de um governo, que preza sua dignidade, ter um órgão próprio, em que se apresente discutindo em face do país, do que entrar em obscuros contratos com empresas particulares, ou procurar corrompê-las, desmoralizando a imprensa, esse primeiro móvel da civilização, e a mais forte garantia das públicas liberdades. (A ACTUALIDADE, 21 jan. 1860, p. 1).

Dessa forma, a A Actualidade irá "agredir" - já que viam a imprensa e o espaço público como uma "arena" - o procedimento do governo de se apre- 
sentar formal e publicamente apenas nas sessões da tribuna que se reunia de oito em oito meses:

A tribuna em nosso país não é arena suficiente para o governo bater-se com os seus adversários; oito meses de intervalo entre as sessões são um espaço por demais longo, para que durante ele os atos do governo possam sem inconveniente deixar de ser discutidos, e para que as censuras, que lhe são dirigidas, fiquem sem resposta.

$[\ldots]$

O gabinete, se ainda não perdeu toda a esperança de vida e saúde, se ainda não está, como se diz, esperando a cada instante pelo transe da agonia, não pode nem deve deixar seus atos indefesos, não pode prescindir de órgão oficial de publicidade, que pleiteie à sua causa. (A ACTUALIDADE, 21 jan. 1860, p. 1).

A postura vigilante do periódico em questão também se espraia para o tema educacional. A educação escolar era um tema bastante caro para aqueles sujeitos. Ressalta Faria Filho (2004) que os redatores d'A Actualidade cobriram com extremo interesse a reforma da instrução pública que aconteceu, no fim da década de 1850, na província de Minas Gerais.

Fizeram, inclusive, duras críticas ao Regulamento $n^{\circ} 44$, introdutor de grandes modificações na organização e na nomeação dos graus e dos professores da instrução primária, mudanças estas que, segundo os redatores, eram confusas e desnecessárias. Essas críticas aparecem na folha do dia $1^{\circ}$ de agosto de 1859, na matéria "O novo regulamento da instrução pública da província de Minas Gerais". Segundo os redatores:

Uma das mais flagrantes provas, de que a administração pública da província de Minas Gerais, está inteiramente abandonada a incúria, ao mau senso, à inépcia de alguns homens, é o novo regulamento de instrução pública, que hoje ali vigora, elaborado pelo Sr. Diretor geral da Instrução publica, hoje - Agente Geral - Rodrigo José Ferreira Brettas, e aprovado pelo Sr. Conselheiro Carneiro de Campos. É desnecessário aqui fazermos sentir a importância e gravidade desse ramo do serviço público, para fazer sobressair a grande responsabilidade, que pesa sobre os administradores daquela província, que assim abandonam essa tão delicada parte da administração pública a um homem que para isso não mostra o menor tino, a menor habilitação, que assim sancionam todos os deletérios de um cérebro, cheio de concepções abstrusas, de ridículas manias, e de estranhas 
aberrações. Quanto a nós, julgamos que seria mil vezes mais conveniente, que o governo largasse mão do ensino público naquela província, e o abandonasse completamente à indústria particular, do que regulá-lo por semelhante modo. (A ACTUALIDADE, $1^{\circ}$ ago. 1859 , p. 2).

Ao abordarem as colocações do regulamento propriamente dito, os redatores ainda fariam mais críticas. Ao dizer que a "nova nomenclatura, longe de ter sobre a antiga o mérito da maior clareza, e precisão lógica, é pelo contrário vaga, incorreta, e pela maior parte injustificável", concluem que:

Entretanto é lastimoso, que em uma província tão ilustrada continue em vigor um regulamento cujo menor inconveniente é o que tem de pueril, e de abstruso em sua forma. Ousamos pedir à presidência daquela província, que a bem dos interesses da numerosa e inteligente mocidade mineira mande suspender a execução daquele regulamento, e proponha à Assembleia Provincial a sua revogação.

Quando tivermos tempo e espaço em nossa folha, voltaremos a este fatigante assunto, e mostraremos o que há de absurdo e incongruente em muitas disposições daquele regulamento; iremos ainda analisando outras inúmeras lindezas, que formigam nesse campo, que deixamos quase intacto; tão fecundo é ele em absurdos. Julgamos que assim faremos um serviço importante àquela malfadada província. (A ACTUALIDADE, $1^{\circ}$ ago. 1859, p. 3$)$

É interessante notar que a confusão causada pelo Regulamento $n^{\circ} 44$ também não passou despercebida pela assembleia provincial que realizaria, posteriormente, debates em que vários parlamentares defenderam sua modificação, conforme atesta matéria publicada pela mesma folha em 28 de novembro de 1860 .

\section{Trajetórias intelectuais pós- $A$ Actualidade}

Com o fim do periódico, Lafaiete Rodrigues continua a pensar a nação, como bom discípulo da Academia de Direito de São Paulo que foi, mas não mais pela forma do jornalismo, mas sim "por dentro" do funcionamento do próprio 
Estado. Ocupou, a partir da visibilidade que conquistou em sua participação n'A Actualidade, dentre outros motivos, importantes cargos políticos. Exerceu a presidência do Ceará entre 1864 e 1865, e a do Maranhão entre 1865 e 1866.

Regressando ao Rio, Lafaiete Rodrigues Pereira foi um dos fundadores do Partido Republicano em dezembro de 1870; mais tarde foi diplomata e conselheiro de Estado. Também foi eleito em $1^{\circ}$ de maio de 1909 para a Cadeira $\mathrm{n}^{\circ}$ 23 da Academia Brasileira de Letras, na sucessão a Machado de Assis. Faleceu no Rio de Janeiro em 29 de janeiro de 1917.

Já Bernardo Guimarães, outro mineiro que codirigiu a folha liberal $A A c$ tualidade, ao fim de sua atuação jornalística, assim como Lafaiete, também foi nomeado para ocupar um cargo ligado ao Estado, como juiz de paz em Goiás, entre 1861 e 1863 . No entanto não seguiu adiante e a partir daí foi professor de retórica e poética em Ouro Preto e Queluz. Na verdade a atuação principal de Bernardo Guimarães, ao longo desse novo período de sua vida, foi a publicação de romances pela editora Garnier. Acreditamos que não seja por acaso que uma das faces mais bem demarcadas de sua produção literária (tanto a poética como a narrativa), entre 1869 e 1872, foi justamente a preocupação com a nação, conforme argumento em minha tese de doutorado (ZICA, 2011). Sem dúvida resquícios de sua passagem pela Faculdade de Direito.

Dos personagens masculinos produzidos por Bernardo Guimarães entre 1871 e 1872, apenas dois não têm um final trágico, emblema das dificuldades com que os sujeitos masculinos lidavam com as novidades na distribuição dos papéis de gênero que naquele período passavam a conviver com as antigas formas dessa distribuição. Os amantes infiéis de Lina e Jupira morrem por meio da vingança delas, respectivamente, em A Garganta do Inferno (1871) e Jupira (1872). Roberto, o primo ciumento e inseguro da protagonista Paulina, suicida-se; e Eduardo, negociante de mulas que a abandona, sugere-se que tenha enlouquecido e morrido num convento após presenciar a morte da mesma Paulina em A filha do fazendeiro (1872). Eugênio, em O Seminarista (1872), também termina a história na condição de louco. Na disputa apresentada pelo romance entre os planos dos pais de Eugênio de torná-lo padre e os desejos do rapaz, contrários àqueles planos, os projetos paternos saem vencedores, quadro que resulta na perda de sua sanidade mental.

Já ao acompanharmos mais de perto as características dos dois personagens de Bernardo Guimarães com destinos menos trágicos - Anselmo, no conto Uma História de Quilombolas (1871), e Elias, no romance O Garimpeiro (1872) -, podemos ver o quanto os dois se assemelham na relação que têm com a nação, já vinculada pelo autor à figura do Estado. Desde o início de $O$ Garimpeiro, o protagonista Elias ressalta a possibilidade dos cidadãos serem úteis com suas ações para o Estado, até mesmo com ações violentas, tais como eram repre- 
sentadas na cavalhada pelas cenas com lanças, espadas e punhais. Ao final do romance, o próprio Elias, em conformidade com suas palavras, irá agir em nome desse Estado, ao denunciar o moedeiro falso, Leonel. O autor mineiro faz, inclusive, coincidirem as motivações pessoais do protagonista com as motivações do Estado para agir daquela forma. Leonel tanto precisava ser contido porque lesava o Estado, quanto porque iria se casar com Lúcia através de um contrato com o pai dela e não pela livre vontade da moça, já que ela amava a Elias. A ação do protagonista protege tanto o bom funcionamento do Estado quanto o bem-estar de sua amada.

É interessante atentar para o fato de que essa mesma associação entre amor romântico, heroísmo masculino - agressivo, em certa medida - e utilidade ao Estado também estava presente no conto Uma História de Quilombolas, publicado um ano antes pelo próprio Bernardo Guimarães, junto de outros dois contos sob o título único de Lendas e Romances (1871), história que se passaria na região de Vila Rica em fins do século XVIII. Anselmo é um mulato livre e namora a bonita escrava Lucinda, cujo proprietário é um Capitão não nomeado, com o qual ele se dá bem e com quem já tinha acertado de comprar a alforria da tal moça para se casarem. Porém um escravo do Capitão, Cabra Matheus, o odiava por ter lhe roubado Lucinda, que, por sua vez, nunca o quisera como companheiro. O tal Matheus foge para um quilombo e reúne alguns parceiros para raptar Lucinda.

Para salvar sua amada, Anselmo segue, sozinho, as pistas deixadas pelos quilombolas até encontrá-los. Tenta comprá-la dos membros do Quilombo, mas não consegue, tornando-se prisioneiro de Zambi Cassange, o líder do lugar. Ao ver que não conseguiria fazer nada para recuperar Lucinda naquelas circunstâncias, resolve fugir, sempre correndo grandes riscos.

Chama atenção o fato de que, após a fuga, Anselmo não hesita em "voar à Vila-Rica a informar o governador e pedir providências para dar no quilombo e libertar sua querida Florinda" (GUIMARÃES, [19--], p. 69). Ou seja, em outra história, a felicidade do casal está também ligada de certa maneira à "felicidade do Estado". Mais uma vez um rapaz representado como bondoso, justo, corajoso e agressivo, se necessário, se faz útil ao Estado ao mesmo tempo em que tenta garantir sua felicidade.

Se a preocupação com a nação/Estado permaneceu claramente na atuação dos dois bacharéis citados após o término d'A Actualidade, poderíamos dizer o mesmo do terceiro integrante do grupo, Flávio Farnese? Dele não conseguimos localizar muitas informações. Talvez, também, por que morrera muito prematuramente.

Morreu no ano de 1871, dez anos após o término da folha liberal em torno da qual os três se engajaram politicamente atuando a partir da Corte do Império. 
Um indício de que a preocupação com as questões nacionais permaneceu com aquele sujeito ao longo dos dez anos pós- $A$ Actualidade, é a presença de sua assinatura no manifesto que inaugurou o Partido Republicano em dezembro de 1870. Outro indício é o de que essa preocupação com a missão nacional, incorporada pelo jornal que dirigiram, seja o eixo central da memória desse sujeito produzida por um de seus companheiros, Bernardo Guimarães, em poesia escrita na ocasião de sua morte, em 1871.

Nessa "escrita final", no poema "A morte de Flávio Farnese" (1876), Bernardo Guimarães (1959, p. 295-298) representa Farnese em sua atuação jornalística muito elogiosamente como um soldado em meio a uma batalha na qual luta pelo bem-estar da pátria:

Era um atleta; - desd'a verde idade Lutando sem cessar em liça aberta Nos santos arraiais da liberdade $\mathrm{O}$ vimos sempre alerta.

Era um atleta, um lidador valente

Esse, que aí jaz dormindo eternamente.

Inda no primo albor da juventude $\mathrm{O}$ austero moço via com tristeza Naufragar da nação toda a virtude No charco da baixeza;

\section{[...]}

Dos filhos do progresso ei-lo na frente Contra o oculto inimigo se revolta, $\mathrm{E}$ ao perigo, que antolha-se eminente, Do alarma o grito solta.

Ei-lo, que se dedica generoso

De nobre luta às escabrosas lidas;

Brande da imprensa o facho luminoso

Ante as turbas dormidas

Da indiferença na letal modorra.

Como réstia de luz, que o sol enfia

Entre as grades de lúgubre masmorra,

Da frase sua o ardor e a valentia

Do povo ao coração levou a crença,

$\mathrm{E}$ os gelos derreteu da indiferença. 
Audaz empunha o cálamo de ferro,

E com pujante frase

Afronta a corrupção, fulmina o erro,

E ataca pela base

Da autocracia o velho balurte,

Que, em mal! - inda vigora em tanta parte.

Por seu talento másculo movida

A pluma se converte em férrea clava,

Que o servilismo e a corrupção trucida,

E a sepultura ao despotismo cava.

\section{Considerações finais}

Conforme procuramos elucidar, inaugurada em 1827, a Faculdade de Direito de São Paulo surge com o propósito de superar a antiga dependência do Brasil em relação a Portugal. Esperava-se dos alunos que, por ela passassem, protagonizassem um movimento não só de renovação da legislação e da administração pública do Império do Brasil recém-surgido, mas também de construção de uma mentalidade acerca da nação brasileira.

Após as análises feitas, fica bastante nítida a influência dessa instituição na vida desses sujeitos que se engajaram na produção de um jornal para intervirem nas questões nacionais. Sujeitos que procuraram, com os meios disponíveis no momento, cumprir essa missão nacional confiada a eles durante o período de formação na referida Faculdade. Foi assim que os temas da educação e imprensa se entrelaçam a essa ambição nacional estampada nas páginas d'A Actualidade. Missão que não terminou com o fechamento do jornal em 1861.

\section{REFERÊNCIAS}

ADORNO, S. Os aprendizes do poder: o bacharelismo liberal na política brasileira. Rio de Janeiro: Paz e Terra, 1988.

BARBOSA, S. de F. P. Jornal e Literatura: a imprensa brasileira no século XIX. Porto Alegre: Nova Prova, 2007. 
CHAMON, C. S. Festejos Imperiais: festas cívicas em Minas Gerais na primeira metade do século XIX. Belo Horizonte: FAFICH/UFMG, 1996.

FARIA FILHO, L. M. de. Bernardo Guimarães: literatura e crítica social no século XIX. UFMG/PUC Rio, 2004. (relatório de pós-doutorado).

GARMES, H. Os Ensaios Literários (1847-1850) e o periodismo acadêmico em São Paulo de 1833 a 1860. 1993. Dissertação (Mestrado em Literatura Brasileira) - Universidade Estadual de Campinas, Campinas. 1993.

LOURO, G. L. O cinema como pedagogia. In: LOPES, E. M.; FARIA FILHO, L. M.; VEIGA, C. G. (Orgs.). 500 anos de educação no Brasil. 2. ed. Belo Horizonte: Autêntica, 2000. p. 423-446.

PALLARES-BURKE, M. L. G. A imprensa periódica como uma empresa educativa no século XIX. In: Cadernos de Pesquisa, n. 104, p. 144-161, jul. 1998.

SÁ, C. M. de. Teatro idealizado, teatro possível: uma estratégia educativa em Ouro Preto (1850-1860). Belo Horizonte: FAE/UFMG, 2009.

SCHWARCZ, L. M. O espetáculo das raças: cientistas, instituições e questão racial no Brasil 1870-1930. São Paulo: Cia das Letras, 1993.

ZICA, M. da C. e. Diversificação dos modos de ser masculino e estatização da violência masculina na escrita literária e jornalística de Bernardo Guimarães (1869-1872). 2011. Tese (doutorado em Educação) - Faculdade de Educação, Universidade Federal de Minas Gerais, Belo Horizonte. 2011.

\section{Documentos consultados}

A ACTUALIDADE, Rio de Janeiro, n. 14, 23 abr. 1859. Rio de Janeiro: Biblioteca Nacional. [microfilme].

A ACTUALIDADE, Rio de Janeiro, n. 26, 8 jun. 1859. Rio de Janeiro: Biblioteca Nacional. [microfilme].

A ACTUALIDADE, Rio de Janeiro, n. 41, $1^{\circ}$ ago. 1859. Rio de Janeiro: Biblioteca Nacional. [microfilme].

A ACTUALIDADE, Rio de Janeiro, n. 54, $1^{\circ}$ out. 1859. Rio de Janeiro: Biblioteca Nacional. [Microfilme].

A ACTUALIDADE, Rio de Janeiro, n. 65, 21 jan. 1860. Rio de Janeiro: Biblioteca Nacional. [microfilme]. 


\section{Textos Literários}

GUIMARÃES, B. Uma História de Quilombolas. In: GUIMARÃES, B. Lendas e Romances. Rio de Janeiro: Garnier, [19--]. (Primeira ed. 1871).

GUIMARÃES, B. A Garganta do Inferno. In: GUIMARÃES, B. Lendas e Romances. Rio de Janeiro: Garnier, [19--]. (Primeira ed. 1871).

GUIMARÃES, B. A morte de Flávio Farnese. In: GUIMARÃES, B. Poesias Completas (1852-1883). (Org. Alphonsus de Guimarães Filho). Rio de Janeiro: INL, 1959. p. 295 298. (Primeira ed. 1876).

GUIMARÃES, B. Jupira. In: GUIMARÃES, B. Histórias e Tradições da provincia de Minas Geraes. Rio de Janeiro: Civilização Brasileira, 1976. (Primeira ed. 1872).

GUIMARÃES, B. A Filha do Fazendeiro. In: GUIMARÃES, B. Histórias e Tradições da província de Minas Geraes. Rio de Janeiro: Civilização Brasileira, 1976. (Primeira ed. 1872).

GUIMARÃES, B. O Seminarista. São Paulo: Ática, 1980. (Primeira ed. 1872).

GUIMARÃES, B. O Garimpeiro. São Paulo: Ática, 1980. (Primeira ed. 1872).

Texto recebido em 2 de junho de 2017. Texto aprovado em 16 de junho de 2017. 
